
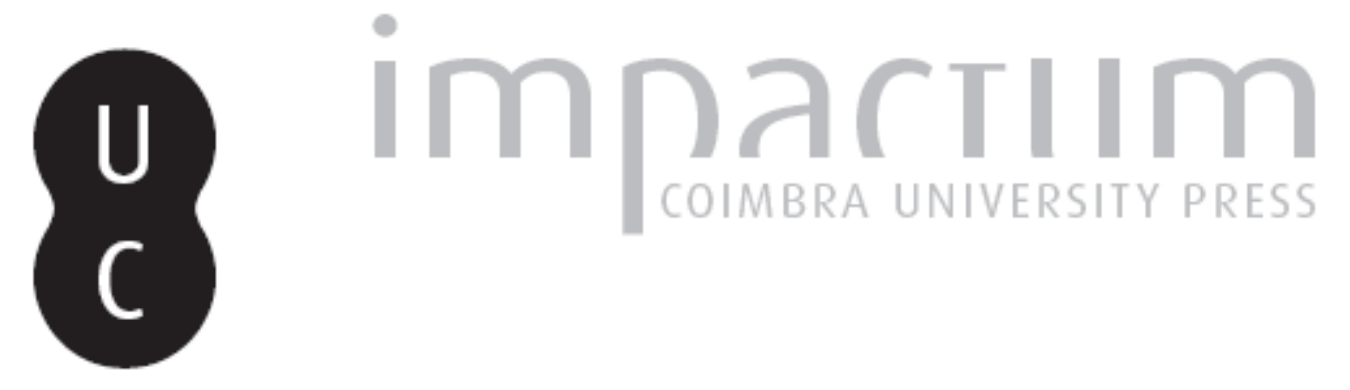

\title{
O lugar da proximidade nos planos de formação em Jornalismo
}

\author{
Autor(es): $\quad$ Coelho, Pedro
}

Publicado por: Imprensa da Universidade de Coimbra

URL persistente:

URI:http://hdl.handle.net/10316.2/39023

DOI:

DOI:http://dx.doi.org/10.14195/2183-5462_28_6

Accessed : $\quad$ 26-Apr-2023 10:26:30

A navegação consulta e descarregamento dos títulos inseridos nas Bibliotecas Digitais UC Digitalis, UC Pombalina e UC Impactum, pressupõem a aceitação plena e sem reservas dos Termos e Condições de Uso destas Bibliotecas Digitais, disponíveis em https://digitalis.uc.pt/pt-pt/termos.

Conforme exposto nos referidos Termos e Condições de Uso, o descarregamento de títulos de acesso restrito requer uma licença válida de autorização devendo o utilizador aceder ao(s) documento(s) a partir de um endereço de IP da instituição detentora da supramencionada licença.

Ao utilizador é apenas permitido o descarregamento para uso pessoal, pelo que o emprego do(s) título(s) descarregado(s) para outro fim, designadamente comercial, carece de autorização do respetivo autor ou editor da obra.

Na medida em que todas as obras da UC Digitalis se encontram protegidas pelo Código do Direito de Autor e Direitos Conexos e demais legislação aplicável, toda a cópia, parcial ou total, deste documento, nos casos em que é legalmente admitida, deverá conter ou fazer-se acompanhar por este aviso.

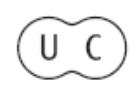




\section{Media 2 Jornalismo}

\section{A DIMENSÃO LABORATORIAL DO ENSINO DO JORNALISMO}




\title{
0 LUGAR DA PROXIMIDADE NOS PLANOS DE FORMAÇÃO EM JORNALISMO \\ THE PLACE OF PROXIMITY IN JOURNALISM \\ TRAINING PROGRAMS
}

\author{
PEDRO COELHO \\ PEDROCOELHO@SIC.IMPRESA.PT \\ UNL/FCSH/DCC \\ SIC TV
}

Resumo

A associação do jornalismo à Internet abre novo espaço à ação comunicativa e, como tal, torna, uma vez mais, possível a reconstrução do espaço público a partir da nova interação entre públicos, permitida pelas plataformas digitais. As comunidades de proximidade estão especialmente vocacionadas para aproveitarem esta dinâmica, recriando-se a partir da base tecnológica que deve ser usada pelos meios de comunicação social locais. Neste contexto, torna-se decisivo que a academia gere alianças estratégicas com as comunidades de acolhimento, participando na formação de jornalistas que ultrapassem o paroquialismo que caracteriza os universos de proximidade.

\author{
Palavras-chave \\ Jornalismo; Academia; Proximidade; Interação.
}

\begin{abstract}
The association between journalism and the Internet generates a new communication process which once again enables the public sphere reconfiguration, using digital public interaction as its pattern. Due to their identity, local communities could facilitate digital communication process promoted by their own media. Nevertheless, it's crucial that a strategic alliance should be carried out by the Academy, involving its host communities, developing journalism education plans that overtake parochialism, which usually distinguishes local geographies.
\end{abstract}

KEYWORDS

Journalism; Academy; Localism; Interaction. 


\title{
0 LUGAR DA PROXIMIDADE NOS PLANOS DE FORMAÇÃO EM JORNALISMO \\ THE PLACE OF PROXIMITY IN JOURNALISM \\ TRAINING PROGRAMS
}

\author{
PEDRO COELHO \\ PEDROCOELHO@SIC.IMPRESA.PT \\ UNL/FCSH/DCC \\ SIC TV
}

\section{Introdução}

0 ensino do jornalismo só chegou a Portugal depois da revolução de 1974 e da queda da ditadura.

Num sobrevoo relâmpago às principais marcas históricas associadas à formação académica em jornalismo é possível concluir que, no período anterior ao 25 abril de 1974, os únicos dois momentos em que, verdadeiramente, se colocou a formação académica na ordem do dia aconteceram por intermédio da classe jornalística, ambos por iniciativa direta do Sindicato Nacional de Jornalistas. A primeira tentativa falhada ocorreu em 1941, a segunda em 1971'. Poderemos encontrar, no fio condutor da história da ditadura, outros momentos em que o debate sobre 0 ensino do jornalismo, de alguma forma, se radicalizou (Sobreira: 2004: 25), elevando 0 tom da discussão, mas a formação académica em jornalismo raras vezes terá perturbado a apatia promovida pelo regime. A solidez das propostas diluía-se nos debates espúrios no seio da classe, amparados, claro está, pelo desejo em manter tudo na mesma: uma entrada na profissão controlada pelo argumento do talento inato, onde a avaliação subjetiva do empregador abria a porta ao acesso empurrado pela cunha, própria dos regimes onde a meritocracia é a ameaça que pode fragilizar os alicerces onde assenta o conformismo. A alimentar a inação da classe estava, igualmente, o hiper-conservadorismo dos "jornalistas instalados", que receariam que a invasão das redações por jornalistas formados em escolas específicas pusesse em causa o estatuto conquistado (Sousa, 2009: 17); por outro lado, se a passividade era 0 alimento da ditadura (Pinto e Sousa, 2003: 174), jornalistas dóceis, mantidos em estado de menoridade (Sobreira, 2004: 33), promoviam melhor essa passividade do que jornalistas cultos, despertos para a crítica e para a promoção de uma sociedade civil ágil e atuante.

No pré-25 de abril, nos momentos em que, historicamente, foi possível escapar aos anátemas da tarimba, elevando o tom do debate, detetamos sinais de uma classe mobilizada em torno da necessidade de ensino formal, com o propósito claro de elevar o estatuto profissional (Mesquita e Ponte, 1997: 11). 0 prestígio e a dignificação profissionais, se mobilizaram a classe jornalística, pelo menos a parcela

1 Sobre este assunto conferir (Mesquita e Ponte, 1997; Correia, 1998b; Pinto e Sousa, 2003; Sobreira; 2004; Pinto, 2004; Cascais, 2008; Marinho e Pinto, 2009; Marinho, 2011). 
que resistia à apatia, terão mobilizado, embora em sentido inverso, não apenas 0 regime, mas também os empresários. Como salienta João Carlos Correia, "a introdução do ensino superior obrigaria à dignificação dos profissionais em termos remuneratórios e em termos da sua capacidade de intervenção" (1998b: 2); alojar a formação dos jornalistas na academia abriria a possibilidade de uma entidade externa ao mercado e, em larga medida, também ao poder político, poder influenciar a identidade de uma classe que se exigia dócil e ordeira.

Em 1979, com o lançamento do curso de Comunicação Social da Universidade Nova de Lisboa, a academia deu o primeiro passo na escalada de inversão dessa lógica atávica imposta pela ditadura; mas, ironia da história, os jornalistas ficaram de fora. Desde logo, e por essa razão, se acentuou o fosso entre os profissionais e a academia.

Ao ficarem afastados da primeira formação na área, os profissionais perderam a possibilidade de a influenciar; criticaram-na, afastando-se do modelo que ela propunha.

0 fosso estará hoje mais atenuado, mas permanece. Tal não impediu que em Portugal, como noutras geografias europeias - Espanha, e Inglaterra, principalmente - e nos Estados Unidos, a realidade se tenha encarregado de estabelecer como critério preferencial de acesso à profissão a licenciatura na área (Fidalgo, 2004: 69; Garcia, 2009: 85; Marinho, 2011: 463; Pinto, 2004: 56; Subtil, 2009: 94).

Entre 1979, data da inauguração do primeiro curso de comunicação em Portugal, e 2009, o número de vagas cresceu de 40 (Comunicação Social, Universidade Nova de Lisboa, Faculdade de Ciências Sociais e Humanas) para 1661, e o número de cursos, que enunciam o acesso à profissão de jornalista, fixou-se nos 31, ministrados em 30 estabelecimentos de ensino, oito universidades públicas, 12 privadas; oito politécnicos públicos, dois privados.

Nos anos 80 do século passado, assumindo como modelo o curso da Universidade Nova de Lisboa, foram surgindo diversas ofertas semelhantes. A explosão, que Mário Mesquita classificaria, em 1995², como "o milagre da multiplicação dos cursos", só aconteceria quase uma década depois, a partir do final dos anos 80, depois dos reflexos da adesão de Portugal à então Comunidade Económica Europeia.

A partir de finais dos anos 70 do século passado, já depois do jornalismo impresso ter vivido a idade de ouro, um novo paradigma económico produz alteraç̧ões sociais relevantes, com efeitos diretos no jornalismo, na formação e nos media. A desregulamentação aumentou o peso da iniciativa privada na comunicação social. 0 mercado do lucro jornalístico alargou-se. A revolução tecnológica em marcha (o cabo e 0 satélite) contribuiu para transnacionalizar impérios de comunicação social, de que 0 jornalismo ficaria refém.

Essa reta final do século passado deixa-nos de herança um jornalismo dócil, sem autonomia, submisso ao desejo de rentabilidade máxima, imposta pelos interesses do mercado, incapaz de aplicar, ou fazer apelo, às normas jurídicas que - constitucionalmente - promovem a proteção e a autonomia do jornalista.

São esses anos da desregulamentação dos media, da hiper-concorrência e da hiper-concentração que estão, paradoxalmente, na base do que poderíamos

2 Diário de Notícias, 5 de janeiro de 1995. 
classificar como a segunda vida do ensino do jornalismo, quase um século depois do nascimento oficial, nos Estados Unidos, da formação académica na área.

David Nolan assinala, exatamente, a pressão dos empregadores sobre a academia para "que forme licenciados dotados de competências técnicas" (2008: 733, 734). James Carey acerta no alvo: os jornalistas hoje têm mais formação, mas menor autonomia (2000).

0 ensino do jornalismo generalizou-se e padronizou-se; viveu o período da mcdonaldização (Papathanassopoulos , 2009: pos. 4060).

Mesmo que a academia conserve a ilusão de ter uma agenda própria, cada vez mais os programas ficam reféns das necessidades efémeras do mercado. Ainda que o mercado precise do alimento da mão-de-obra produzida na academia, a construção de barreiras entre os dois mundos continua a ser desenhada dentro e fora da academia, gerando, por essa via, um processo de formação frágil, incompleto e condicionado; mas é desse subproduto que a indústria se alimenta.

0 advento das novas tecnologias digitais e a associação destas ao jornalismo é o tempo certo para a terceira vida do ensino do jornalismo. É neste contexto que devemos enquadrar a temática da proximidade e as preocupações que o estudo deste campo específico deve transportar para os planos curriculares.

\section{Escassa Representatividade da Proximidade na Oferta Curricular Existente}

No estudo que fizemos, com vista à concretização da nossa investigação de doutoramento, analisámos a oferta curricular existente na academia portuguesa em jornalismo-comunicação, no ano letivo de 2009-2010³. Cada uma das propostas curriculares foi agrupada numa das três áreas de estudo que caracterizámos: jornalismo; comunicação e ciências sociais e humanas. 0 campo da comunicação revelou-se o campo maioritário, agrupando 18 das licenciaturas (idem, ibidem: 366).

0 campo específico da proximidade está presente, unicamente, num dos estabelecimentos de ensino com cursos na área, na Escola Superior de Educação de Portalegre, no curso de Jornalismo e Comunicação. A escola oferece a unidade curricular (uc) de Comunicação Social Local e Regional".

Existindo uma rede de escolas descentralizada, com a oferta na área a cobrir diversas comunidades de proximidade no interior norte e centro e no litoral centro, a escassa representatividade do campo específico da proximidade ainda menos se compreende, sobretudo num cenário dominado pela crescente precariedade laboral e pelos fortes sinais de excesso de oferta que emergem na comunicação social nacional ${ }^{5}$.

3 A classificação das licenciaturas e a sua integração em cada um dos três campos ocorreu apenas no ano letivo de 2012-2013, numa fase em que o número das propostas curriculares na área tinha baixado de 31 para 27.

4 http://www.esep.pt/documentos/Plano\%20de\%20Estudos/Licenciatura\%20em\%20Jornalismo\%20e\%20Comunica\%C3\%A7\%C3\%A30_.pdf

5 Em Portugal não existem dados concretos sobre o impacto do desemprego na classe. 0 número de desempregados registado não corresponde ao número real porque, como admitem Rebelo et al, muitos jornalistas omitem a situação de desempregado no processo de busca de um novo emprego, 
A integração do campo específico da proximidade, num ambiente jornalístico fragilizado pelo mercado e pela dificuldade em associar as novas tecnologias digitais à ação quotidiana, carece, todavia, de um outro olhar sobre os planos de formação que, na nossa aceção, ultrapassa, largamente, a simples introdução de uma unidade curricular que prefigure a especificidade da ação jornalística fora dos grandes centros. Desenvolveremos essa temática em etapa posterior; nesta fase importa apreendermos os elementos distintivos das comunidades de proximidade e a forma como os meios de comunicação social se posicionam nesses universos de interação.

\section{A Especificidade das Comunidades de Proximidade}

Os meios de comunicação social deveriam ser os instrumentos por excelência de ampliação do debate e da discussão racionais, ainda que, como Wright Mills nos alertava na década de 50 do século passado, as interligações que se estabeleceram entre 0 jornalismo, o lucro, os media e a sociedade de massas tivessem impedido a progressão desse potencial (1956: 368, 369). Em tese, todavia, a base dos meios de comunicação social é a promoção da comunicação racional entre os agentes sociais, assumindo aqueles o papel de guardiães do espaço público, no sentido em que fiscalizam o poder e os seus representantes, criticando-0s, se tal for necessário, ou iluminando o caminho de todos os que participam nesse exercício. É a comunicação racional que faz progredir o espaço público e essa comunicação racional deveria ser intermediada pelos meios de comunicação social.

Os meios de comunicação social promovem espaços públicos de diferentes dimensões; todavia, o potencial comunicativo, intermediado pelos meios de comunicação social, que está na base da estruturação do espaço público, enquanto modelo de ação comunicativa, alimentada pela troca racional de argumentos entre os diversos membros que 0 integram, tem especial expressão nas comunidades de proximidade. Os meios de comunicação social de proximidade, jornais, rádios, televisões, apresentam características típicas do jornalismo pré-industrial (Correia, 1998a: 158), onde, de forma mais efetiva, o jornalismo pôde afirmar-se motor dos processos comunicativos.

A comunidade é o lugar da identidade comum; os indivíduos que integram determinada comunidade, herdeiros dos princípios que estão na base da formação dessa identidade comum, desenvolvem, em nome dela, um compromisso, um pacto (Moragas, 2000: 27), estabelecido com vista à concretização de um determinado objetivo, ou seja, o progresso dessa comunidade. Ora esse conceito de comunidade, enquanto lugar de proximidade onde se estabelecem relações sociais entre forças conflituantes, rejeita o falso "consenso" imposto pelas elites locais e que nestas comunidades de proximidade nasce quase sempre do interconhecimento nelas favorecido. Este conceito de comunidade resulta do pacto estabelecido en-

trocando-a pela situação de regime livre (2011: 78). 0 dado mais concreto sobre a precariedade da classe foi apresentado pelo Sindicato dos Jornalistas: entre 2007 e 2011 o número de jornalistas que requereu o subsídio de desemprego, ou o subsídio social de desemprego, situou-se nos 694 (Sindicato dos Jornalistas, 2012), cerca de 10 por cento do número total de jornalistas (Rebelo et al, 2011: 57). 
tre os indivíduos que a compõem sem que desse pacto resulte a marginalização do conflito; esta comunidade aceita a diversidade de opiniões e o inter-relacionamento com outras comunidades. Robert Boure e Alain Lefebvre descrevem-na enquanto "lugar específico que se distingue dos outros lugares pelas singularidades ligadas à sua origem, à sua construção, mas também à sua localização no espaço", todas as condições que, no fundo, assinalam o nascimento e promovem essa identidade comum a que nos referíamos. Este lugar, como assinalam os autores, não é um "gueto", pelo contrário, "é aberto sobre os outros lugares e sobre aquilo que muitos consideram ser o espaço-mundo"(2000: 270). É um lugar de interação, de ação comunicativa, entre os elementos que o integram e entre eles e todos os outros, de todos os lugares.

Admitamos, portanto, segundo a concetualização aqui apresentada, que 0 indivíduo, que participa e se envolve na concretização do objetivo comum, veja a sua ação reforçada nas pequenas comunidades locais, não só pela maior proximidade entre 0 topo e a base da pirâmide social, o que não deve ser, necessariamente, um obstáculo ao conflito, mas também pela possibilidade de, integrando o outro, o diferente, serem mais facilmente representadas as diversas sensibilidades locais.

Neste contexto, a ideia clássica de região é muito mais do que um espaço físico comummente assinalado como a dimensão imediatamente inferior ao Estado-Nação. A região, ou o território que a forma, é "sobretudo uma relação entre pessoas, um espaço de apropriação e de identificação, uma construção social permanente" (Ramírez, 2000: 15). A comunicação é, assim, a base que torna possível essa interação entre os diversos atores sociais que ocupam o território de determinada região. Só a comunicação permite a sobrevivência e a progressão da região. Como refere Bougnoux, "a comunicação destina-se, em primeiro lugar, a organizar a relação social, a estruturar a vida quotidiana e a manter a coesão da comunidade" (apud Camponês, 2000: 111).

0 problema, como aliás salientámos numa investigação anterior, onde avaliámos o papel dos meios de comunicação social nos espaços públicos de proximidade, está na especificidade desses contextos sociais. A realidade local, que então descrevemos, parece caminhar no sentido oposto à criação de um verdadeiro espaço público, dada a convivial cumplicidade de interesses entre as elites locais e os meios de comunicação social de proximidade, o que, desde logo, promove um espaço público deformado (Coelho, 2005: 232).

A integração da proximidade nos planos de formação de primeiro ciclo dos cursos da área de jornalismo-comunicação, justifica-se, também pela necessidade de dotar o jornalista, que atua profissionalmente fora dos grandes centros, dos instrumentos que lhe permitam ultrapassar os constrangimentos associados às comunidades de proximidade (idem, ibidem: 158-163).

\section{As Novas Tecnologias Digitais e o Potencial de Valorização do Público}

As novas tecnologias digitais vieram acentuar o peso do mercado, porque a tecnologia, sobretudo na imprensa escrita, contribuiu para afastar os anunciantes. 
Assistimos àquilo que Bill Kovach e Tom Rosenstiel classificaram como "o fim do acidente feliz", em que um bem privado sustentou um bem público (2010:13). De facto, a Internet revela dificuldades em gerar receitas financeiras perenes.

Se o cabo e 0 satélite aumentaram a velocidade da informação, globalizando-a, com a Internet a velocidade traz associada a mistura de mensagens de proveniências distintas, gerando o "caos informacional" de que nos fala Érick Neveu (2001: 123).

A crise do jornalismo no século XXI não é uma crise de audiências. É uma crise de sustentabilidade financeira. É, de novo, o mercado a impor o seu grilhão.

Convém, notar, todavia, que as marcas de referência permanecem como as mais consultadas e estão em marcha ações de complementaridade entre novas e velhas plataformas, residindo nessas ações o futuro do jornalismo. Como veremos, esse futuro deve ser construído a partir da formação académica e, em algumas geografias, como a norte-americana, é já visível uma aliança estratégica entre a academia e a ação profissional quotidiana, que tem especial reflexo nas comunidades de proximidade.

A internet veio acrescentar um potencial de interatividade, desde logo uma dimensão promotora de reconstrução do jornalismo, que, ao mesmo tempo, acabou por ter influência direta nos meios de comunicação tradicionais.

A integração da tecnologia no processo permite, finalmente, acertar o foco: 0 jornalismo é consequência de existir um público ávido de notícias para poder interagir/comunicar; o jornalismo promove essa comunicação.

As novas tecnologias tornam possível a interatividade. Mas essa possibilidade, encarada exclusivamente do ponto de vista tecnológico, é mero apetrecho. Se não existisse uma disponibilidade (e um interesse) dos públicos em usarem esse potencial, os novos dispositivos perderiam o seu valor de uso.

A vontade de participar não é tecnológica. Sempre existiu. Os meios tradicionais apenas coartavam essa possibilidade, forçando a existência, num público ativo e disponível para participar, de um imobilismo, mas, de facto, apenas aparente. Determinadas parcelas da sociedade recusaram render-se a essa inatividade de base tecnológica, rompendo os grilhões impostos pela unidirecionalidade: "As máquinas não mudam a natureza humana" (Kovach, Rosenstiel, 2007: 184).

A imagem abrangente do recetor passivo, que consome mensagens sem nenhum grau de reflexão associado, não passará, pois, de um estereótipo.

João Pissarra Esteves deteta sinais de uma pulsão "emancipatória" de públicos resistentes que, desde o século XIX, força a releitura de uma ideia cristalizada de crise associada ao espaço público e que, ao mesmo tempo, abre brechas nesse muro ideológico (2011: 281).

Essas subculturas excluídas aguardariam, apenas, que um qualquer dispositivo tecnológico Ihes permitisse romper as baias, espalhar a mensagem, influenciar, em suma, participar. Os públicos alternativos afirmaram-se muito antes do advento da Internet, formando comunidades específicas de interesses comuns (associações cívicas, movimentos sociais, partidos políticos fora do sistema), mas a Internet permitiu-lhes a visibilidade que precisavam para se legitimarem.

Bill Kovach e Tom Rosenstiel enaltecem o potencial aberto pelas novas tecnologias no reforço da cidadania e da própria democracia, permitindo a participação 
de um público que sempre resistiu à unidirecionalidade; acreditam, aliás, que um jornalismo centrado no público, e amparado pela Internet, promova o alargamento dessa esfera cívica e, afirmando o seu poder de motor agregador da comunicação, refundar a esfera pública (2010: 201). Como considera Mark Deuze, a orientação para 0 diálogo afasta 0 jornalismo do princípio clássico - "dar às pessoas o que elas precisam de saber" - e aproxima-o do ideal de James Carey - "a amplificação do diálogo que a sociedade tem com ela própria" (2005: 455 e 456).

Os movimentos de resistência que, ao longo das épocas, despontaram na esfera pública, rejeitando os padrões de organização em que esta assentava o modelo e a própria base, contribuíram, como vimos, para manter viva a possibilidade de regeneração dessa esfera pública. Esses movimentos de resistência ampliaram a voz, legitimaram a ação, através dos media. Os media, revelam, pois, o seu papel ambivalente (Esteves, 2011: 279): simultaneamente produtores de um consenso social artificial, que, de alguma forma, os implica na manutenção do estado das coisas, e veículos de resistência.

De alguma forma, essa integração dos atores sociais, desencaixados do espetro de acesso aos media, ocorre de forma episódica e sem que esse acesso ponha em causa a própria lógica de funcionamento dos meios de comunicação social. Subsiste uma certa espetacularização como ímpeto promotor desse acesso. Molotch e Lester explicam-nos que "0 acesso aos media é um bem estratificado socialmente", como tal, "os que não têm praticamente nenhum poder devem perturbar a ordem social para incomodar as formas habituais de produção dos acontecimentos" (apud Traquina, 1999: 173). A perturbação da ordem social, através de manifestações, cortes de estrada, ocupação das sedes de organismos públicos ou privados, etc., tem associado 0 inesperado espetacular que se enquadra nos critérios de noticiabilidade dos media. Os movimentos sociais de resistência cultivam essa atitude de perturbação da ordem pública para acederem ao palco dos media; nessas condições, os media acolhem-nos.

A lógica que perpassa a essência do jornalismo de proximidade, e dos próprios meios de comunicação social de proximidade, é essa, a de tornar visíveis territórios que os grandes meios marginalizam e onde só investem quando um elemento disruptivo perturba o quotidiano.

Como assinala António Fidalgo, em Portugal, a falta de visibilidade, "a penumbra pública", com que as regiões mais pobres se debatem, afeta diretamente o seu potencial de crescimento, fragilizando-0 (2000: 102).

Na reta final dos anos 90, Artur Merayo, um professor de Comunicação da Universidade de Salamanca, traçava o roteiro de uma outra dinâmica de interação entre os meios de comunicação social de proximidade e as comunidades que, à época, permaneciam na penumbra. Merayo assinalava, então, que as televisões que emitem a partir de Lisboa "têm uma visão metropolitana do país, reservando os acontecimentos locais para segundo plano, a não ser que sejam tragédias. Neste sentido, tudo o que não é Lisboa aparece, quase sempre, com um sentido negativo". 0 investigador comparava, a invisibilidade pública do interior português àquela a que 0 ocidente vota 0 terceiro mundo. Artur Merayo defendia, por isso, a criação em Portugal de televisões de proximidade mas que emitissem conteúdos de proximidade, verdadeiramente alternativos, uma vez que são esses os omitidos pelas 
cadeias nacionais e os únicos com capacidade para satisfazerem as necessidades comunicacionais das populações isoladas. ${ }^{6}$

As rádios locais, a seu tempo vozes alternativas que romperam os grilhões da unidirecionalidade, tornando visíveis, pelo menos aos olhos das comunidades de origem, territórios que permaneciam silenciosamente na penumbra, foram - na década de 80 do século passado - esse rastilho de esperança que, mesmo episodicamente, iluminou, consolidou e desenvolveu comunidades. 0 espírito perdeu-se, mas a história é testemunha do sucesso da sua fugaz emancipação.

Se públicos resistentes suplantaram os constrangimentos da esfera pública, quando os meios de comunicação social, ao invés de abrirem brechas, a fechavam sobre si própria, novos públicos poderão, nesta era digital, disfrutar do potencial tecnológico para comunicarem, trocarem experiências, influenciarem, desafiarem as verdades absolutas que toldam a ação política. E poderão (deverão) fazê-lo, igualmente, nos media tradicionais.

Precisamos de um novo cidadão, de um novo jornalista, de uma nova arquitetura de meios. Em suma, de um novo jornalismo. As bases desse novo jornalismo devem ser encontradas na academia.

\section{Por um Modelo de Formação que Salvaguarde o Jornalismo de Proximidade}

A nossa proposta pressupõe uma articulação direta entre o primeiro e o segundo ciclos, partindo do princípio de que a conclusão do primeiro ciclo não prepara 0 aluno para uma integração autónoma no mercado. Essa maior interligação entre os dois ciclos, ao mesmo tempo que, no segundo ciclo, abre uma via de investimento na especialização em áreas de interesse do futuro profissional, de que a proximidade constitui um exemplo, elege o estágio elemento de ligação ao mercado ${ }^{7}$; a um outro nível, o segundo ciclo pode criar, igualmente, as condições para um trajeto académico mais centrado na investigação. É neste cenário, de articulação entre os dois ciclos de estudo, valorizando uma formação geral (de base) no primeiro ciclo, e a formação especializada no segundo, que devemos encarar a formação no campo específico da proximidade.

0 curso de ciências da comunicação, variante de jornalismo, deve adotar um tronco comum nos primeiros três semestres, devendo 0 aluno ter a possibilidade

6 A Capital, 10 de fevereiro e 21 de abril de 1997.

70 estágio curricular formal, promotor da primeira interseção autónoma no mercado, em períodos de três meses, ou superiores, deve ocorrer, apenas, no final do segundo ciclo. Entendemos que o contacto com o mercado é, igualmente, fundamental para o aluno de primeiro ciclo, mas este deve ser estabelecido de forma faseada e progressiva, ao longo de todo o percurso letivo. Na lógica da aproximação progressiva ao mercado, que defendemos no nosso modelo, a permanência dos alunos na redação deve ir aumentando à medida que as uc, classificadas como práticas, adquiram uma maior expressão nos planos curriculares, devendo, no terceiro ano, existir um período máximo de permanência do aluno na redação de um mês, coincidindo com o final do ano letivo, podendo ocorrer entre 15 de junho e 15 de setembro, de forma a que as notas finais possam ser lançadas até final de setembro. Essa permanência na redação deve estar associada a uma das unidades curriculares do terceiro ano que reflita a maior aproximação à profissão. 
de começar a frequentar unidades curriculares específicas da variante a partir do quarto semestre. Libertadas da componente exclusivamente prática, que caracteriza a maioria das uc da variante de jornalismo nos cursos que analisámos na nossa investigação de doutoramento, e estabelecendo interligações com a comunicação e com as ciências sociais e humanas, que Ihes garantem maior abrangência, as unidades curriculares de jornalismo poderão, assim, assumir uma maior expressão nos planos de estudo. Neste sentido, a nossa proposta prevê a atribuição de um peso semelhante à variante e ao tronco comum ${ }^{8}$.

Ao nível do tronco comum, a nossa proposta recupera parte da oferta já identificada nos diversos $\operatorname{cursos}^{9}$ e sublinha a necessidade de existirem outras unidades complementares ${ }^{10}$ que, no essencial, afirmam a comunicação como a casa natural do jornalismo, valorizam a dimensão do público e a correspondente componente ética e clarificam as fronteiras entre jornalismo, relações públicas e publicidade.

Neste conjunto de propostas têm especial incidência na temática da proximidade duas unidades curriculares: Público, Cidadania e Ética Profissional e Portugal Contemporâneo no Contexto Global.

A uc Público, Cidadania e Ética Profissional detalha a nova centralidade do público, consagrada pela ação das novas tecnologias digitais. A partilha de saberes comuns, a troca racional de argumentos, que alimenta a comunicação, pode, enfim ser concretizada por intermédio de dispositivos tecnológicos mediáticos que a ampliam, reforçando os vínculos entre os membros de comunidades específicas de alcance potencialmente global.

0 aluno deve despertar para esta centralidade do público e refletir sobre o papel que, enquanto profissional de comunicação, Ihe compete exercer para promover, de facto, processos de comunicação. Desde logo, esta unidade curricular deve alertar 0 aluno para a necessidade de dotar o público com os instrumentos que the permitam participar. Esta uc deve, para tal, assumir um investimento na literacia mediática, um saber específico a requerer continuação na variante, cujo propósito é iluminar a ação do público, permitindo-Ihe assumir o novo estatuto na produção de mensagens mediáticas.

A nova centralidade do público força a assunção de um novo compromisso com a ética profissional, não apenas porque a tecnologia digital abre 0 acesso às profissões da comunicação aos que, anteriormente, estavam remetidos à receção pas-

8 Na nossa proposta, o tronco comum soma 75 créditos e a variante 85, totalizando 160 créditos. Para completar os restantes 20, 0 aluno pode selecionar unidades curriculares de entre a oferta do estabelecimento de ensino de acolhimento do curso, incluindo unidades das outras variantes; em ambos os casos, o aluno pode investir em áreas de interesse individual, ou que considere complementares do jornalismo. A seleção desses 20 créditos pode gerar um aprofundamento da articulação com o segundo ciclo, se a escolha promover a constituição de uma base teórica de áreas especializadas do jornalismo.

9 Comunicação e Ciências Sociais; Teoria da Comunicação; Sociologia da Comunicação; Antropologia da Comunicação; Filosofia da Comunicação; Economia da Informação; Semiótica; Discurso dos Media.

10 História da Comunicação; Público, Cidadania e Ética Profissional; Jornalismo/Relações Públicas e Publicidade; Comunicação e Política; Portugal Contemporâneo no Contexto Global; Literatura e Narrativas Visuais. 
siva, o que associa ao processo de produção de conteúdos uma miríade de novos agentes, cuja participação requer supervisão e, sobretudo, verificação dos conteúdos produzidos, mas também porque o digital permite a explosão de mensagens; a ética profissional é o selo distintivo de credibilidade, que legitima a mensagem junto dos destinatários.

A uc Portugal Contemporâneo no Contexto Global é especialmente determinante na introdução de um percurso de estudo específico no domínio da proximidade. Neste âmbito, a rede de interconexões suscitada na imersão das identidades nacionais num contexto global, impõe-nos uma reflexão clara sobre a matriz do posicionamento de Portugal no contexto da Europa e do mundo. Esta unidade curricular apresenta ao aluno as principais tendências da globalização, refletindo sobre as suas consequências na identidade nacional. A disciplina propõe, igualmente, o início de um percurso de questionamento, que deve ser continuado na variante, sobre a influência da cultura ocidental na estruturação do pensamento global e consequente marginalização de outras linhas de pensamento. A uc deve iniciar também a discussão sobre identidade nacional, comunidade, nacionalismos, xenofobia e exclusão social.

A variante reforça a componente reflexiva, estabelecendo uma ponte direta com os quadros concetuais trabalhados no tronco comum. Essa dimensão reflexiva incorpora o estudo da missão e valores do jornalismo e a avaliação dos efeitos do mercado e da tecnologia na ação quotidiana. A partir desta incorporação, a variante deve trabalhar a dimensão do público e a comunicação gerada no decurso do processo de produção informativo ${ }^{11}$.

0 ensino do jornalismo deve afirmar, por fim, o primado dos géneros jornalísticos e não o das plataformas distribuidoras; 0 jornalismo não deve ficar refém da forma, imposta pela especificidade dessas plataformas, mesmo que os alunos devam desenvolver competências que Ihes permitam adaptar a ação profissional quotidiana aos diversos meios ${ }^{12}$.

0 investimento dos programas nos géneros jornalísticos deve estabelecer compromisso, sobretudo, com a reportagem. Estas abordagens serão testadas, no final do percurso académico de primeiro ciclo, no laboratório privilegiado da academia. Esta dimensão laboratorial do plano de estudos é, como lhe chama Carlos Chaparro, a "espinha dorsal" do curso - o espaço de atração e de integração das diversas vertentes do saber, exploradas ao longo do processo formativo (apud Pinto, 2004: $101-103)^{13}$.

11 Esses saberes deverão ser trabalhados nas uc de Jornalismo e Mercado; Jornalismo e Tecnologia; Funcionamento do Estado e Problemas Sociais; Jornalismo, Mutação dos Media e Especificidade das Plataformas Mediáticas; Elementos do Jornalismo; Direito e Deontologia Profissional; Jornalismo e Literacia Mediática; Sustentabilidade do Jornalismo e Empreendedorismo;

12 A afirmação do primado dos géneros jornalísticos deve ser trabalhada nas seguintes uc: A Notícia; A Reportagem; Jornalismo de Investigação e Jornalismo de Proximidade.

13 No âmbito da ação jornalística propomos as seguintes uc e laboratórios: Escrita Jornalística; Laboratório Jornalístico - A Notícia; Laboratório Jornalístico; A Entrevista; Laboratório Jornalístico a Reportagem/Estágio. 
As unidades curriculares que propomos para a variante constituem um polo de vaIorização do jornalismo, distinguindo-o dos demais subcampos específicos da comunicação. A ação jornalística em comunidades de proximidade deve revelar-se transversal ao plano de estudos, sem, todavia, dispensar uma uc específica que associe a reflexão relativa à ação jornalística quotidiana aos contextos de proximidade.

\section{A Unidade Curricular de Jornalismo de Proximidade}

A montante da criação de uma uc específica de jornalismo de proximidade, Karin Wahl-Jorgensen e Thomas Hanitzsch colocam a necessidade de estudar as práticas dos jornalistas locais, estudo que, segundo os autores, "tem sido particularmente negligenciado". Centrando o discurso na realidade europeia, os autores entendem que a política editorial da academia não devia aceitar que as "práticas profissionais colocadas na margem da ação" permaneçam fora do espetro de estudo (2009: 12).

Os argumentos de Simon Frith e Peter Meech parecem justificar essa opção académica. Os autores alertam-nos para uma interpretação da ação jornalística, concretizada fora dos grandes centros, que registou poucas alterações ao longo da história. Frith e Meech consideram que o jornalismo urbano, praticado nos meios de referência, tem tendência a olhar para o jornalismo local como se de uma atividade menor se tratasse: "Subsiste um argumento de classe, que caracteriza os jornalistas nacionais como a elite culta, e os jornalistas locais como os incultos" (2007: 161). Ultrapassado o constrangimento provocado pelo argumento de classe, expresso nessa divisão entre jornalistas de primeira e de segunda, é um facto que a análise do caso português nos transporta para um universo onde a diferença, de facto, existe ${ }^{14}$.

A este propósito, João Carlos Correia considera que a única forma de evitarmos a "condescendência paternalista" com que encaramos a ação dos media nos espaços públicos de proximidade é investir na formação dos jornalistas que exercem a sua ação fora dos grandes centros: "As regiões e o jornalismo que nelas se pratica pressupõem especificidades que não devem (...) implicar cedências na formação dos jornalistas" (1998a: 8).

Associada ao frágil estatuto profissional dos jornalistas de proximidade está a fragilidade económica dos próprios meios e as dependências que estes têm de assumir, relativamente às elites locais, para conseguirem sobreviver ${ }^{15}$.

14 A nossa própria experiência profissional e académica ajuda-nos a confirmar esta visão. Na SIC, estação de televisão onde trabalhamos desde 1992, a maioria dos correspondentes locais das delegações cumpre tarefas jornalísticas quotidianas, estando-lhes vedada a concretização de trabalhos complexos, que requerem competências que a estação entende que eles não têm. 0 trabalho académico que desenvolvemos, para concretização da nossa investigação de mestrado, descreve uma classe profissional a atuar fora dos grandes centros que acumula o jornalismo com o exercício de outras profissões, a maioria sem formação académica específica e revelando fortes sinais de dependência face às elites locais (Coelho, 2005: 165 e 166).

15 Na nossa investigação de mestrado detalhámos a relação de cumplicidade que os meios de comunicação social de proximidade, em nome da sobrevivência dos próprios projetos informativos, estabelecem com as elites locais, rejeitando integrar as opiniões marginais que possam por em causa 0 estado das coisas. Como, então, escrevemos, "As relações sociais nos espaços de proximidade 
Sem novos meios de proximidade, financeiramente mais maduros, socialmente mais atuantes, jornalisticamente relevantes, dificilmente teremos novos jornalistas. A realidade, todavia, redesenha-se mercê da influência de fatores externos, também eles mutantes. No trabalho que publicámos em 2005, defendemos a intervenção do Estado, apoiando, sem esperar contrapartidas políticas, o jornalismo de proximidade, depois de um trabalho de seleção dos órgãos de comunicação social que, realmente, prestassem um serviço à comunidade, contribuindo para o seu desenvolvimento (Coelho, 2005: 204). Não o tendo aceitado antes, o quadro de crise que atravessamos dificilmente levará o Estado a aceitar agora esse desafio. A economia local não é, todavia, uma realidade de expressão idêntica em todas as regiões do país, existindo centros económicos pujantes, com capacidade de criarem riqueza, e, com ela, alimentarem a existência de uma massa crítica, cujas ideias circulem pelo espaço mediático de proximidade, cada vez mais aberto e acessível. A unidade curricular que, no nosso modelo, associámos ao empreendedorismo, deve despertar nos alunos o desafio de criarem o seu próprio negócio. Ora, o espaço público de proximidade pode ser 0 ideal para desenvolver esses projetos.

Na nossa ótica, a necessidade de formar jornalistas capacitados para interpretarem a idiossincrasia das comunidades de proximidade, agindo em conformidade, é pois, e por demais, evidente.

A unidade curricular que propomos não pretende encarar o jornalismo, praticado fora dos grandes centros, como uma atividade diferente, onde os valores da profissão, de repente, sejam substituídos por outros, deturpadores da ação quotidiana; insistimos neste ponto: o jornalismo permanece, independentemente do meio, do espaço, ou do regime político onde é exercido. Se a plataforma não pressupõe, em nosso entender, a existência de uma formação específica, o regime político e a identidade das comunidades de proximidade forçam os jornalistas a tomarem consciência das limitações impostas à sua ação profissional, com o propósito claro de preservar os valores que a moldam.

Brooke Kroeger parece identificar bem o problema quando defende programas de formação em jornalismo que "combatam o paroquialismo local" (2002: 2), de facto uma perversão social que resume a idiossincrasia dominante no espaço público de proximidade.

\section{Pontes: Cursos de Jornalismo - Comunidades de Acolhimento}

Um primeiro ciclo de estudos na área de jornalismo-comunicação representa 0 início de uma caminhada. Como tal, importa construir uma base, um ponto de partida sólido e efetivo, cuja âncora seja a valorização do jornalismo e a proteção da complexidade que lhe está associada. A partir desta base de sustentação, todas as articulações são possíveis. 0 segundo ciclo, lugar da especialização e da interseção com o mercado, que, por via do estágio, promove a primeira integração au-

respondem muitas vezes, seguramente vezes de mais, à velha máxima quem não está comigo é contra mim. Com isto eternizam-se as elites no poder, demonstrando estas à saciedade que todas as ações que desempenham são assumidas em nome da comunidade, e, submetendo-se os meios de comunicação social a essa mesma máxima, silencia-se a contra-argumentação enaltecendo-se 0 trabalho das elites com a emissão de uma mensagem única" (Coelho, 2005: 165). 
tónoma do aluno com 0 ambiente profissional, deve ser a sequência lógica deste ponto de arranque.

Afirmando a proteção do jornalismo como a essência, o primeiro ciclo de estudos parte da relação que o jornalismo estabelece com a democracia e analisa, sobretudo, os fatores externos que mais diretamente o influenciam. Neste sentido, as relações entre 0 jornalismo e o mercado e a dinâmica criada pelas novas tecnologias digitais, com a introdução dos públicos no processo produtivo, permitindo ao jornalismo afirmar-se (finalmente) motor da comunicação, são matérias transversais ao plano de estudos. É neste contexto, de transversalidade, que devemos integrar o campo específico da proximidade. Ainda que um segundo ciclo debruçado sobre esta área de estudo deva promover um aprofundamento (especialização) na temática, a base deve ser estruturada no primeiro ciclo, nos moldes que definimos neste presente trabalho.

Em Portugal, a rede descentralizada de escolas com cursos de jornalismo-comunicação permite que algumas delas assumam o jornalismo de proximidade como área de especialização. Entendemos que, nestes casos, deve ser estabelecido um compromisso direto entre o programa de estudos e as comunidades de acolhimento. A plena descodificação da identidade da comunidade de acolhimento do curso (componente letiva) deve ser aliada à criação de pontes com os meios de comunicação social que servem essa comunidade, ou ao desenvolvimento de órgãos próprios, parceiros estratégicos da comunidade de acolhimento (componente estágio/investigação).

Neste contexto, o programa de estudos deve transformar-se num agente de desenvolvimento, animando projetos jornalísticos que promovam a discussão, a troca de ideias, e que questionem as elites, integrando no debate as opiniões dos agentes sociais que, habitualmente, são excluídos dos processos de decisão.Num trabalho publicado em 2005, apresentámos as vantagens de uma aliança entre os órgãos de comunicação social de proximidade (televisões de proximidade) e as universidades e institutos politécnicos, com cursos na área, que servem essas comunidades. Os cursos deveriam ser parceiros dos meios de comunicação social de proximidade, formando quadros, produzindo conteúdos e testando, em laboratório, novas abordagens jornalísticas e tecnológicas de apoio à ação profissional. Dessa parceria deveria resultar, igualmente, a criação de postos de trabalho, contribuindo para que alguns profissionais da região pudessem fixar-se nas comunidades de origem (Coelho, 2005: 205 e 206).

No relatório que produziram em conjunto sobre a reconstrução do jornalismo norte-americano, Leonard Downie Jr. e Michael Schudson valorizam aspetos da realidade que analisam, relativos ao envolvimento dos cursos de jornalismo com as comunidades de acolhimento, que vêm ao encontro do que nós próprios defendemos em 2005. Os autores alargam, todavia, 0 âmbito das pontes estabelecidas entre a universidade e a comunidade, mercê do desempenho das novas plataformas digitais:

"Um número crescente de universidades publica as reportagens dos seus estudantes nos diversos canais do Estado, da cidade, do bairro onde a escola está inserida. Os estudantes trabalham na faculdade e nos órgãos locais sob supervisão 
de jornalistas profissionais, que, entretanto, estabeleceram canais de ligação à universidade. As reportagens dos estudantes são publicadas nos sítios online de notícias locais da universidade e dos outros meios de proximidade" (2009: 59).

A observação das experiências norte-americanas, envolvendo a universidade e as comunidades de proximidade, levou os autores do relatório sobre a reconstrução do jornalismo americano a sugerirem um apoio público a projetos jornalísticos não lucrativos, especialmente de âmbito local, que realmente sirvam 0 interesse público (idem, ibidem: 77, 94).

Tendo por base a realidade europeia na viragem do século, Angelo Agostini, à época vice-presidente da Associação Europeia de Formação em Jornalismo, destacava, exatamente, o papel da universidade na produção de informação de serviço público, com efeitos sociais relevantes nas comunidades:

“De facto, muitas escolas intensificaram a produção de informação ao nível local, fornecendo às comunidades, onde estão sediadas, um conjunto de vozes jornalísticas independentes e socialmente saudáveis. As escolas de jornalismo estão, aliás, a transformar-se num ator determinante na difusão do conhecimento, que garantirá às comunidades o acesso à sociedade da informação" (1997: 1 e 2).

A produção do relatório sobre o estado do jornalismo americano e o esforço de definição de um roteiro alternativo, de reconstrução do jornalismo, conduziu Downie Jr. e Schudson a um exercício crítico detalhado, mas, igualmente, à valorização de algumas experiências que, no entender de ambos, poderiam preconizar traços efetivos de reconstrução do jornalismo. Os exemplos que então identificaram são os que põem em prática um princípio de interligação entre valores e tecnologia. Na sua maioria são meios pequenos com uma estrutura leve e dinâmica, ancorados em múltiplas fontes de financiamento: investimento público, investimento privado, subsídios concedidos por fundações e por universidades, investimento das comunidades de acolhimento desses projetos, publicidade, subscrições e parcerias internas e externas, que permitem aplicar o princípio da economia de escala.

Estes exemplos de sucesso correspondem à realidade americana, muito distante da portuguesa; o conceito, contudo, merece atenção analítica.

São diversas as experiências analisadas. Algumas delas desenvolvidas em comunidades de proximidade:

1) Jornalistas veteranos, que não resistiram aos cortes nas empresas onde trabalhavam, ou que, pura e simplesmente, decidiram romper com a lógica imposta pelo mercado clássico, fundam projetos de jornalismo de investigação ou temáticos. São propostas ainda em fase de teste, financeiramente frágeis, mas que os autores encaram com otimismo. Estas experiências mostram, porém, que um mercado abrangente e diverso permite ultrapassar os efeitos da crise que afeta o jornalismo; em mercados fechados, como o português, dominados por um pequeno conjunto de grandes grupos de media (tendo em conta a dimensão do país), o espaço para a imposição de projetos alternativos é, obviamente, menor.

2) Ủm outro tipo de projetos identificado resulta da associação de jornalistas profissionais com a comunidade blogger e jornalistas cidadãos. São propostas 
muito associadas a comunidades de proximidade, financiadas pelas próprias comunidades, pela publicidade local e por investidores locais. Esses pequenos meios especializam-se em notícias locais, alcançando elevado estatuto local. Respondem ao desafio de tratar com profunda abrangência um pequeno número de assuntos. Os resultados começam a ser visíveis. Alguns desses meios, como o Voice of San Diego, produzem investigações jornalísticas com efeitos socialmente relevantes na vida da comunidade.

0 grau de profundidade de cobertura das temáticas chega a ser de tal forma visível, que esses pequenos meios alternativos conseguem colocar esses conteúdos na agenda dos meios tradicionais. Nesses casos, as abordagens alternativas são publicadas em órgãos de comunicação social maiores, com quem esses meios estabelecem parcerias.

Alguns desses pequenos meios locais funcionam, igualmente, como uma central de produção de conteúdos que distribuem nas diversas plataformas locais. Estas propostas comunitárias apresentam uma característica comum: um pequeno grupo de jornalistas profissionais trabalha diretamente com a comunidade na recolha e tratamento dos conteúdos. Na maioria dos casos, os conteúdos dos cidadãos são verificados e tratados pelos profissionais; os cidadãos são, sobretudo, responsáveis pela recolha de informação (Downie Jr. e Schudson, 2009: 35-44).

Estes projetos locais e hiper locais preenchem o espaço deixado vago pelos cortes assumidos pelos jornais metropolitanos, que reduziram as redações e, consequentemente, encerraram as delegações locais.

3) Os cursos universitários de jornalismo estão profundamente implicados nesta reconstrução do jornalismo americano. Nos casos destacados pelos autores do relatório, os estudantes produzem conteúdos jornalísticos relativos à comunidade onde a universidade está sediada. Esses conteúdos, trabalhados em ambiente de sala de aula e supervisionados pelos professores, são posteriormente publicados nos meios informativos locais, ou nos meios da própria universidade. 0 jornalismo universitário desempenha, assim, uma tripla função: laboratório, fonte de informação da comunidade e de atração de doadores. A universidade afirma-se, igualmente, como lugar de acolhimento de projetos independentes de reportagem de investigação, alguns tutelados por antigos jornalistas (idem, ibidem: 59 e 60, 62).

\section{Conclusão}

A proximidade deve, pois, ser encarada como uma oportunidade.

Na nossa investigação de doutoramento identificámos alguns exemplos profundamente marcantes do desinvestimento nesta área específica ao nível da formação académica. Desde logo, um desconhecimento dos alunos, promotor de desinteresse na área e do que ela representa. Esse desconhecimento conduz a maioria dos estagiários a colocarem a comunicação social de proximidade como hipótese remota de integração na profissão.

Essas marcas são bem visíveis no depoimento da aluna Carolina Moreira, do curso de Ciências da Comunicação, da Universidade Nova de Lisboa, a cumprir um estágio profissional de seis meses na TSF Açores. A aluna, que integrou o nosso painel de 67 alunos, que monitorizámos no decurso do ano letivo de 2010-2011, 
sublinhou o grau de isolamento físico e psicológico, desencadeado pelo regresso forçado à terra onde nasceu:

"Vi-me forçada a voltar para cá para conseguir trabalhar na área e ganhar algum dinheiro. Não foi uma decisão fácil, nem está a ser algo que me preencha a sede de trabalho e de aprendizagem. Não é, nem de perto nem de longe, o sítio onde pretendo trabalhar e vingar na área".

Carolina Moreira, o elemento mais ativo da comissão voluntária de estágios do ano letivo de 2010-2011, perdeu o ânimo que a mobilizava enquanto estudante e, no primeiro emprego, sente a frustração da distância, provocada pelo facto de não ter vingado nos estágios que fez nos grandes meios de comunicação social nacionais. Ter emprego remunerado não lhe basta, porque as expectativas foram colocadas num patamar demasiado elevado.

0 caso de Carolina Moreira determina que questionemos a forma como os cursos preparam os alunos para enfrentarem o mercado. A aluna alimentou o sonho legítimo de trabalhar nos meios nacionais e tem dificuldade em enquadrar essa impossibilidade imediata. Em nosso entender, o curso deveria ter-lhe descrito os contornos do mercado e preparado para a possibilidade de um regresso ao lugar de origem, onde porventura poderiam abrir-se as possibilidades de emprego que os grandes meios the negaram. A universidade poderia ter participado na diminuição do grau de frustração da aluna, caso tivesse investido na temática da proximidade, que alimentasse, nos alunos, o desejo do regresso às origens ou, pelo menos, os ajudasse a interagir positivamente com esse regresso, definindo estratégias de desenvolvimento de projetos jornalísticos viáveis, ou apresentando-lhes modelos de participação na recuperação de outros já existentes.

0 nosso estudo sublinha, igualmente, o desencanto dos alunos que optaram por concretizar os seus estágios em meios de comunicação social de proximidade, uma vez que esses meios perpetuam as práticas lesivas que identificámos ao longo deste trabalho e que associámos à fragilidade jornalística e financeira desses projetos.

Esses alunos revelam ambientes profundamente limitadores da progressão profissional. Afirmam que poderiam ter feito estágios atrás de estágios sem que os proprietários dos media os quisessem dispensar. Ao contrário do que se passa nos mcs nacionais, onde nalguns casos subsistem sinais de resistência à utilização do trabalho dos estagiários, nos meios de proximidade, onde não abundam as competências nem os recursos humanos, o estagiário é integrado no processo produtivo como qualquer outro profissional, não recebendo, contudo, nenhuma retribuição pelo trabalho que exerce.

0 futuro das comunidades de proximidade depende, cada vez mais, da capacidade que elas demonstrarem para se tornar distintas, atraindo e conservando massa crítica que absorva um pensamento eclético que promova o crescimento desses lugares de identidade comum. Os meios de comunicação social revelam-se, neste contexto, instrumentos decisivos para atingir esse desiderato. Formar profissionais que colaborem na reconstrução do jornalismo de proximidade, assumindo-o motor da comunicação, é uma missão que a academia não pode, nem deverá, continuar a dispensar. 


\section{Referências Bibliográficas}

AGOSTINI, Angelo, 1997, "A joint perspective; networking the European journalism Schools", in Jan Bierhoff e Mogens Schmidt (org.), European Journalism Training in Transition, the inside view, Maastricht: European Journalism Centre, 1997, 55-59.

BOURE, Robert, LEFEBVRE, 2000, Alain, "Télévisions Locales et Territoires en Mouvement", in Hermès, n. ${ }^{\circ} 26,27$, Paris.

CAMPONEZ, José Carlos, 2000, Jornalismo de Proximidade - Rituais de Comunicação na Imprensa Regional, Dissertação de Mestrado, Lisboa, UNL, FCSH.

CAREY, James W. 2000, "Recensão" de Rich Media, Poor Democracy: Communication Politics in Dubious Times, de Robert W. McChesney, vol 54, n. 2 ("Nieman Reports") 67-68,disponivel em http://www.nieman.harvard.edu/reports/article/101943/ Journalism-and-Democracy-Are-Names-for-the-Same-Thing.aspx (policopiado em fevereiro de 2013).

CASCAIS, Fernando, 2008, "Ensino do jornalismo em Portugal. História de um fracasso dos jornalistas", in Media \& Jornalismo, n. ${ }^{0}$ 13, Lisboa, CIMJ, 55-77.

COELHO, Pedro, 1989, Rádios Locais: Problemas da Opinião Pública e Regionalização, Dissertação de Licenciatura, Lisboa, UNL, FCSH.

COELHO, Pedro, 2005, A TV de Proximidade e os Novos Desafios do Espaço Público, Lisboa, Livros Horizonte.

COELHO, Pedro, 2015, Jornalismo e Mercado, os novos desafios colocados à formação, Covilhã, Labcom Books.

CORREIA, João Carlos (1998b). "0 ensino do jornalismo visto pelos jornalistas", BOCC http:// www.bocc.ubi.pt/pag/correia-joao-ensino-jornalismo.pdf (policopiado em 2010).

CORREIA, João Carlos, (1998a), "Algumas reflexões sobre a formação universitária dos jornalistas", BOCC http://www.bocc.ubi.pt/pag/correia-joao-formacao-universitaria-jornalistas.pdf (policopiado em 2010).

DEUZE, Mark, 2005, "What is journalism?: Professional Identity and ideology of journalists reconsidered", vol. 6, n 4, ("Journalism"), 442-464.

DOWNIE JR., Leonard e SCHUDSON, Michael, 2009, The Reconstruction of American Journalism, ("Columbia Journalism Review"), New York.

ESTEVES, João Pissarra, 2011, Sociologia da comunicação, Lisboa, FCG

FIDALGO, António, 2000, “Fazer Televisão no Interior de Portugal, in Televisión y Desarrollo - las Regiones en la Era Digital, Badajoz, ed. Junta da Extremadura.

FIDALGO, Joaquim, 2004, "Jornalistas: um perfil socioprofissional em mudança", n. ${ }^{0} 5$ (“0 Ensino do Jornalismo, Revista Comunicação e Sociedade"), 63-74.

FRITH, Simon e MEECH, Peter, 2007, "Becoming a journalist - Journalism education and journalism culture", vol. 8, n. ${ }^{0} 2$ ("Journalism"), 137-164.

GARCIA, José Luís; 2009, "Principais tendências de profissionalização dos jornalistas no período pós-transição democrática ", José Luís Garcia (org.), Estudos sobre os Jornalistas Portugueses, Lisboa, Imprensa de Ciências Sociais, 63-91.

HANITZCSCH, Thomas e WAHL-JORGENSEN, Karin, 2009, "Comparative Journalism Studies", in Thomas Hanitzcsch e Karin Wahl-Jorgensen, Karin, (org.), The Handbook of Journalism Studies, New York and London, Routledge 413-428. 
KOVACH, Bill e ROSENSTIEL, Tom, 2007, The Elements of Journalism (completely, updated and revised), New York, Three Rivers Press.

KOVACH, Bill e ROSENSTIEL, Tom, 2010, Blur, how to know what's true in the age of information overload, New York, Bloomsbury.

KROEGER, Brooke, 2002, "Journalism with a scholar's intent", in Amy Atkins; Andrew O'Hehir; Jay Rosen, (org.), Zoned for Debate (essays),New York, NYU, disponível em http://journalism.nyu.edu/publishing/archives/debate/forum.1.index.html, policopiado em outubro de 2005.

MARINHO, Sandra, 2011, Formação em Jornalismo numa Sociedade em Mudança, Tese de Doutoramento em Ciências da Comunicação, Universidade do Minho.

MESQUITA, Mário e PONTE, Cristina, 1996/97, Situação do ensino e da formação profissional na área do jornalismo. Estudo elaborado para a representação da Comissão Europeia em Portugal, disponível em http://bocc.ubi.pt/pag/mesquita-mario-ponte-cristina-Cursos-Com1.html (documento policopiado em novembro de 2009).

MILLS, C. Wright, 1956, A elite do poder, Rio de Janeiro, Zahar, 1981.

NEVEU, Érik, 2001, Sociologia do jornalismo, Porto, Porto Editora, 2005.

NOLAN, David, 2008, "Journalism, education and the formation of 'public subjects", vol. 9, n. ${ }^{\circ} 6$ ("Journalism"), 733-749.

PAPATHANASSOPOULOS, S., 2009, "Introduction: The Mediterranean/Polarized Pluralist Media Model Countries", in Georgios Terzis (org.), European Journalism Education, Chicago, Intellect kindle posição 4724-4881.

PINTO Manuel et al, 2004, "Debater a formação em jornalismo é debater o próprio jornalismo, entrevista com o professor Manuel Chaparro", n. ${ }^{0} 5$ ("0 Ensino do Jornalismo, Revista Comunicação e Sociedade"), 95-107.

PINTO, Manuel, 2004, "0 ensino e a formação na área do jornalismo em Portugal: crise de crescimento e notas programáticas", n. ${ }^{0} 5$ ("0 Ensino do Jornalismo, Comunicação e Sociedade"), 49-62.

PINTO, Manuel e Marinho, S., 2009, "The Portuguese Journalism Education Landscape", in Georgios Terzis (org), European Journalism Education, UK/Chicago: Intellect kindle posição 5353-5744

PINTO, Manuel e Sousa, Helena, 2003, "Journalism education at universities and journalism schools in Portugal", in Romy Fröhlich e Christina Holtz-Bacha (org.), Journalism Education in Europe and North America: an International Comparison, New Jersey: Hampton Press 169-187.

RAMÍREZ, Enrique Bustamante, 2000, "Regiones, Televisión y Desarrollo" in Vacas, Francisco (org), Televisión y Desarrollo - las Regiones en la Era Digital, Badajoz, ed. Junta da Extremadura.

REBELO, José (org.), 2011, Ser Jornalista em Portugal. Perfis Sociológicos. Lisboa, Gradiva. SINDICATO DOS JORNALISTAS, 2012, "Desemprego dos jornalistas agrava-se", disponível em http://www.jornalistas.eu/?n=8905\&imprimir (texto policopiado).

SOBREIRA, R.M., 2004, "0 ensino do jornalismo e a profissionalização dos jornalistas em Portugal (1933-1974)", n. 3 ("Media \& Jornalismo"), 17-36. 
SOUSA, Jorge Pedro, 2009, "A discussão sobre a introdução do ensino superior do jornalismo em Portugal: das primeiras menções ao primeiro curso de graduação", BOCC, disponível em: http://www.bocc.ubi.pt/pag/sousa-jorge-a-discussao-sobre-a-introducao-do-ensino-superior-do-jornalismo-em-portugal.pdf (policopiado em agosto de 2013).

SPÁ, Miguel de Moragas, 2000, "Televiones y Regiones en Desarrollo. Possibilidades en la Era Digital", in Vacas, Francisco (org), Televisión y Desarrollo - las Regiones en la Era Digital, Badajoz, ed. Junta da Extremadura.

SUBTIL, Filipa, 2009, "Anotações sobre o processo de feminização do jornalismo na década de 1990", in José Luís Garcia, (org.), Estudos sobre os jornalistas portugueses, Lisboa, ICS.

TRAQUINA, Nelson, (org.) 1999, Jornalismo: questões, teorias e 'estórias', Lisboa, Vega 